\title{
Study of the lineage structure of building steel by atomic force microscopy
}

\author{
V.V. Duka ${ }^{1}$, L.P. Aref' eva ${ }^{\dagger, 1}$, V.N. Pustovoit ${ }^{1}$, D. A. Kiseleva ${ }^{2}$ \\ †Ludmilochka529@mail.ru \\ ${ }^{1}$ Don State Technical University, 1 Gagarin Sq., Rostov-on-Don, 344000, Russia \\ ${ }^{2}$ Southern Federal University, 105/42 Bolshaya Sadovaya St., Rostov-on-Don, 344006, Russia
}

\begin{abstract}
The paper presents the results of a comprehensive study of micro- and nanostructures of steel by optical and atomic force microscopy methods, carried out in accordance with international standards. The studies were carried out on samples healed in two different ways: complete quenching and quenching from the intercritical interval. The object of the study was structural alloyed building steel 1.0481 with troost-martensitic and ferritic-martensitic structures. The chemical composition of the steel was controlled using method of optical emission spectrometer (Q8 MAGELLAN). Sample preparation for AFM investigations did not include etching. Microstructure studies were performed on optical microscopes Metam RV-22 and Neophot-21. Optical microscopy showed the presence of steel hardened from the intercritical interval in the structure of the sample, and a stitch structure consisting of ferrite and martensite. A quantitative assessment of the hardening phase (martensite) was carried out using the KOI-1 program, intended for the quantitative metallographic analysis of digital photographs of the microstructure of materials. According to stereometric analysis of the microstructure of this sample, the volume fraction of ferrite is $70 \%$. Three-dimensional images of the surface of the samples were obtained by atomic force microscopy (PHYWE Compact AFM) in the tapping mode in an air atmosphere. Next, one-dimensional (texture, roughness, waviness) and statistical parameters of the surface topography (arithmetic average roughness, root mean square roughness, asymmetry, excess) were determined. The method of counting cubes was used to estimate the fractal dimension. A comparative analysis of the data showed that a surface with a stitch structure is more developed and has higher roughness parameters and fractal dimension values than a surface with a homogeneous structure of troost-martensite.
\end{abstract}

Keywords: steel, natural ferrite-martensitic composite (NFMC), atomic-force microscope, stitch structure, fraction dimensional.

УДК: 53.08:620.18

\section{Исследование строчечной структуры строительной стали методом атомно-силовой микроскопии}

\author{
Дука В. В. ${ }^{1}$, Арефьева Л. П. ${ }^{\dagger, 1}$, Пустовойт В. Н. ${ }^{1}$, Киселёва Д. А. ${ }^{2}$ \\ ${ }^{1}$ Донской государственный технический университет, пл. Гагарина, 1, Ростов-на-Дону, 344000, Россия \\ ${ }^{2}$ Южный федеральный университет, ул. Большая Садовая, 105/42, Ростов-на-Дону, 344006, Россия
}

В работе приведены результаты комплексного исследования микро- и наноструктуры стали методами оптической и атомно-силовой микроскопии, проведенными в соответствии с международными стандартами. Исследования проводились на образцах, полученных двумя различными путями: полной закалкой и закалкой из межкритического интервала. Объектом исследования служила конструкционная легированная строительная сталь $14 Г 2$ с троостомартенситной и феррито-мартенситной структурами. Контроль химического состава стали осуществлялся с помощью оптико-эмиссионного спектрометра Q8 MAGELLAN. Препарирование образцов для АСМ исследований не включало операцию травления. Исследования микроструктур выполняли на оптических микроскопах Метам PB-22 и Neophot-21. Оптическая микроскопия показала наличие в структуре образца стали, закаленной из межкритического интервала, строчечной структуры, состоящей из феррита и мартенсита. Количественная оценка упрочняющей фазы (мартенсита) проводилась с использованием программы КОИ-1, предназначенной для количественного металлографического анализа цифровых фотографий микроструктуры материалов. По данным стереометрического анализа микроструктуры данного образца, объемная доля мартенсита составляет $30 \%$. Трехмерные изображения поверхности образцов были получены методом атомно-силовой микроскопии (РНYWЕ Compact AFM) в полуконтактном режиме в воздушной атмосфере. Далее определялись одномерные (текстура, 
шероховатость, волнистость) и статистические параметры рельефа поверхности (средняя арифметическая шероховатость, средняя квадратическая шероховатость, асимметрия, эксцесс). Метод подсчета кубов использовался для оценки фрактальной размерности. Сравнительный анализ полученных данных показал, что поверхность со строчечной структурой несколько более развита и имеет более высокие параметры шероховатости и значения фрактальной размерности, чем поверхность с однородной структурой троосто-мартенсита.

Ключевые слова: сталь, естественный феррито-мартенситный композит (ЕФМК), атомно-силовая микроскопия, строчечность, фрактальная размерность.

Создание композиционных материалов, работающих в сложных эксплуатационных условиях, является актуальной технической задачей.

Естественный феррито-мартенситный композит (ЕФМК) - композит на основе горячекатаной доэвтектоидной стали со строчечной феррито-перлитной структурой, полученный путем закалки стали от температур межкритического интервала (МКИ). Строчечность считается производственным браком, приводящим к анизотропии механических свойств проката. Причиной возникновения строчечности являются вытянутые при прокатке неметаллические включения и ликвационная неоднородность примесей и легирующих элементов, которые являются местами преимущественного зарождения феррита при замедленном охлаждении проката в МКИ [1]. В то же время особенности ЕФМК позволяют получать более высокие показатели хладноломкости, ударной вязкости, работы зарождения и распространения трещины по сравнению со сталью после полной закалки и отпуска [2,3].

Объект исследования работы - ЕФМК, полученный на основе доэвтектоидной стали 14Г2. Химический состав определялся с помощью оптико-эмиссионного спектрометра Q8 MAGELLAN: $0.16 \%$ C, $0.32 \%$ Si, $1.53 \% \mathrm{Mn}, 0.27 \% \mathrm{Ni}, 0.21 \% \mathrm{Cr}, 0.23 \% \mathrm{Cu}, 0.038 \% \mathrm{~S}$, $0.031 \%$ P, 0.06\% As, что соответствует ГОСТ 19281-89 [4].

Марганцовистая строительная сталь 14 Г2 в горячекатаном состоянии, в некоторых случаях, может иметь строчечную феррито-перлитную структуру, используемую для получения ЕФМК.

Причиной возникновения строчечной структуры в стали $14 Г 2$ является присутствие сульфидов марганца и железа, вытянутых вдоль направления прокатки и выполняющих роль подложек при выделении избыточного феррита в процессе охлаждения проката в МКИ. Дополнительный фактор формирования строчечности - ликвация сопутствующих примесей и легирующих элементов.

Одним из перспективных методов исследования поверхности материалов является АСМ [5-15]. В [9-13] показано, что ACM является универсальным инстру- ментом для изучения топологии поверхности сталей и сплавов, позволяет проводить измерения физических параметров и полей, выявлять фазовые составляющие и особенности структуры. С помощью АСМ в комплексе с оптической микроскопией исследовалась эволюция структуры стали 40X13 в состоянии поставки, после закалки и после отпуска $[13,14]$, стали 65ГА и детали из стали У8 [8]. В работе [10] выявлены структурные особенности (пористость, структурные дефекты) углеродистой стали $(0.1 \% \mathrm{C})$.

Фрактальный анализ дает количественную информацию о развитости поверхности, технологических процесcax, в которых происходит формирование структуры, об изменениях, происходящие в деформируемом материале. Фрактальная характеристика шероховатой поверхности инвариантна относительно масштаба измерений [16].

Цель работы - сравнительный анализ образцов стали $14 Г 2$ со структурой ЕФМК и однородной структурой троосто-мартенсита, полученных путем различной термообработки (Табл. 1), методом АСМ и определение параметров поверхности.

Металлографические исследования осуществлялись на продольных шлифах. Во избежание завала кромок образцов при полировке их помещали в зажим (стальные струбцины), образцы малых размеров заливали в оправки сплавом Вуда. Препарирование завершали на шлифовальной бумаге с окончательной полировкой на фетровом круге с использованием пасты ГОИ. Травление образцов выполняли 4-х\% раствором азотной кислоты в этиловом спирте. Просмотр и съемку микроструктур выполняли на микроскопах Метам PB-22 и Neophot-21.

Определение структурных составляющих стали проводили на ACM PHYWE Compact AFM с использованием программы анализа данных Gwyddion, предназначенной для анализа полей высот, полученных сканирующей зондовой микроскопией.

Сканирование поверхности не травленых образцов $10 \times 10 \times 4$ мм проводилось в полуконтактном режиме с использованием кантилевера $190 \mathrm{AL}-\mathrm{G}$ в воздушной атмосфере.

Табл. 1. Режимы термической обработки образцов из стали $14 Г 2$.

Table 1. Modes heat treatment of the samples from steel 1.0481.

\begin{tabular}{|c|c|c|}
\hline Образец / Sample & Термическая обработка / Heat treatment & Структура / Structure \\
\hline \multirow{2}{*}{1} & Закалка $860^{\circ} \mathrm{C}$ (вода) + отпуск $200^{\circ} \mathrm{C}$ & Tроосто-мартенсит \\
& Quenching $860^{\circ} \mathrm{C}$ (water + tempering & ЕФMК \\
\hline \multirow{2}{*}{2} & Закалка $730^{\circ} \mathrm{C}\left(\right.$ вода) + отпуск $200^{\circ} \mathrm{C}$ & NFMC \\
\hline
\end{tabular}


Одномерные параметры текстуры, шероховатости и волнистости определялись с помощью программы Gwyddion в соответствие с ГОСТ Р ИСО 4287-2014 [17]. Одномерная текстура поверхности разбивается на шероховатость (размерная характеристика микронеровностей) и волнистость (периодически возникающие неровности геометрической структуры поверхности). Также проведены измерения статистических параметров рельефа, в том числе асимметрии (скошенность распределения профиля) и эксцесса (протяженность распределения профиля). Фрактальную размерность поверхности определяли по методу подсчета кубов [16].

На Рис. 1 показаны микроструктуры стали 14Г2 после термообработки. Видно, что образец 2 имеет особенности в виде строчечности, представляющей собой чередующиеся слои феррита и мартенсита.

Количественная оценка объемной доли мартенсита в ЕФМК проводилась с использованием программы КОИ-1 (Рис. S1, дополнительный материал). Объемная доля мартенсита составила порядка $29.0 \pm 1.7 \%$, что характерно для используемого температурного режима термообработки.

АСМ изображения образцов 1 и 2 представлены на Рис. 2 и 3.

Для детального анализа получали по пять профилей поверхности каждого образца вдоль осей X и Y изображения (Рис. 4). Видно, что форма и размеры пиков и впадин профилей значительно отличаются. По всей длине образца 1 профиль поверхности имеет одинаковую форму. Профили образца 2 разных участков поверхности имеют отличительные особенности (Рис. 4 b).

Установлено, что одномерная шероховатость и средняя волнистость поверхности образца 1 (Рис. 5) больше шероховатости и средней волнистости образца 2. Заметный вклад в одномерные параметры вносит наличие однородной структуры в образце 1 , дуальной - в образце 2.

Ассиметрия профилей образца 1 меньше, чем образца 2, то есть профили поверхности образца со структурой ЕФМК более несимметричны, но имеют меньшую протяженность распределения (Табл. 2).

Образец со строчечной структурой ЕФМК имеет более развитую поверхность (Табл. 2). Причины заключаются в неоднородности микроструктуры композита: малая объемная доля мартенсита $(29.0 \pm 1.7 \%)$ и большое количество феррита (69.0土1.7\%) (Рис. S1, дополнительный материал) дают большие значения среднеквадратичной шероховатости, фрактальной размерности по сравнению с образцом 1. Значения максимальной глубины впадины сопоставляются с выбранными режимами термообработки. Температурный режим закалки в МКИ позволяет получать высокоуглеродистый мартенсит с высокой микротвердостью (7240 217 МПа, микротвердомер ПМТ-3) и пластичный феррит. При этом, твердость образца 2 по Роквеллу ниже (21.25 $\pm 0.50 \mathrm{HRC})$, чем у однородного

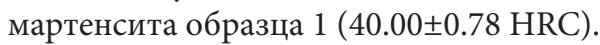

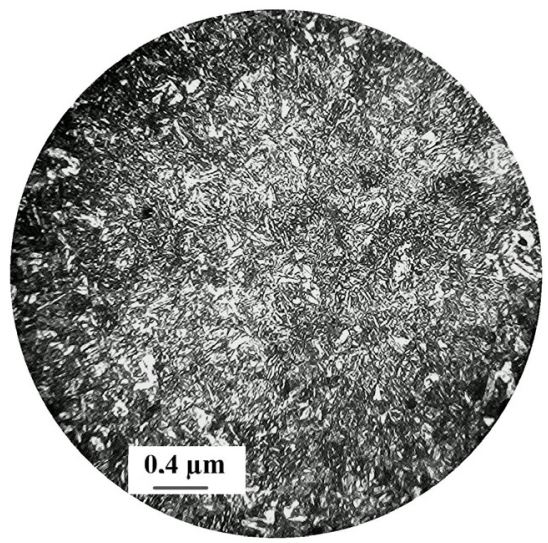

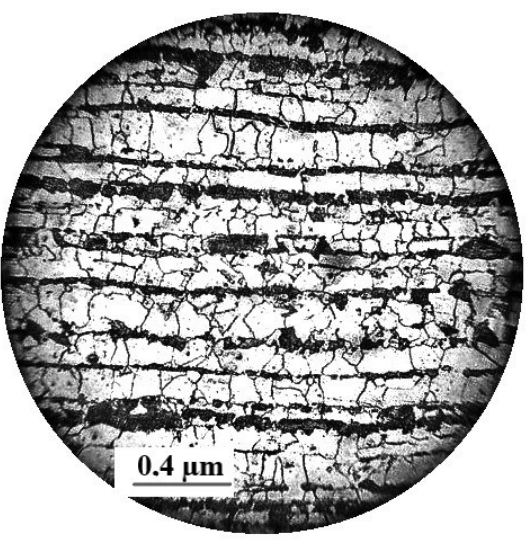

b

Рис. 1. Микроструктура стали $14 Г 2$ после термообработки: образец 1 (a), образец 2 (b).

Fig. 1. Microstructure steel 1.0481 after heat treatment: sample 1 (a), sample 2 (b).

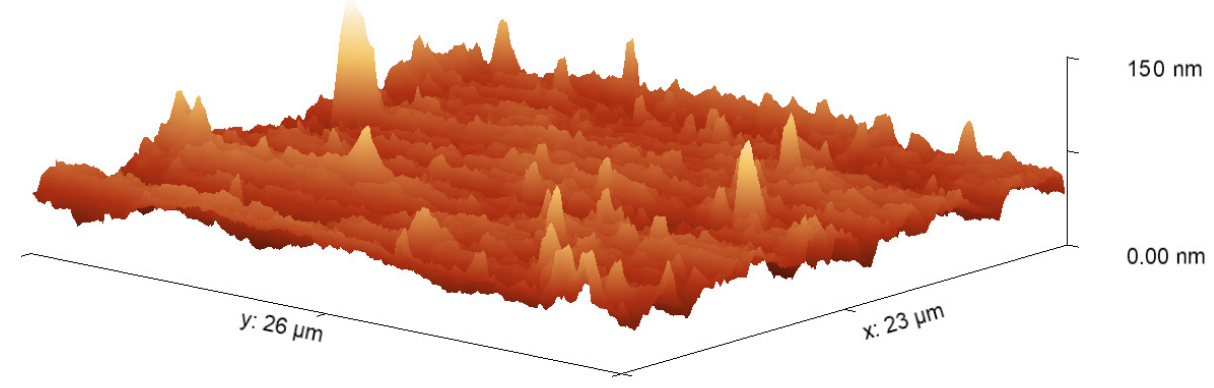

Puc. 2. (Color online) Пример АСМ изображения поверхности стали $14 Г 2$ после полной закалки.

Fig. 2. (Color online) Example of AFM image of surface steel 1.0481 after full quenching. 


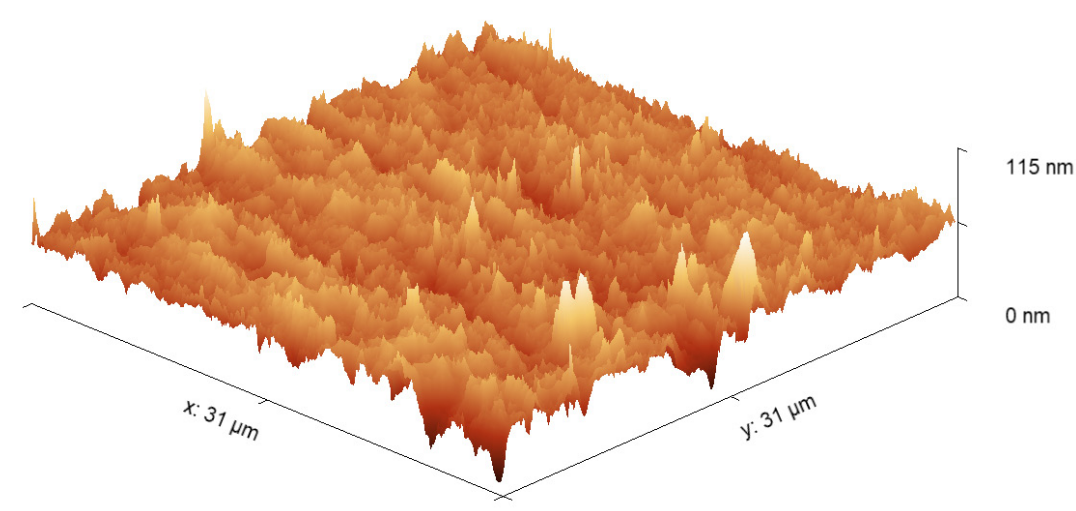

Pис. 3. (Color online) Пример АСМ изображения поверхности стали $14 Г 2$ после неполной закалки.

Fig. 3. (Color online) Example of AFM surface of surface steel 1.0481 after incomplete quenching.

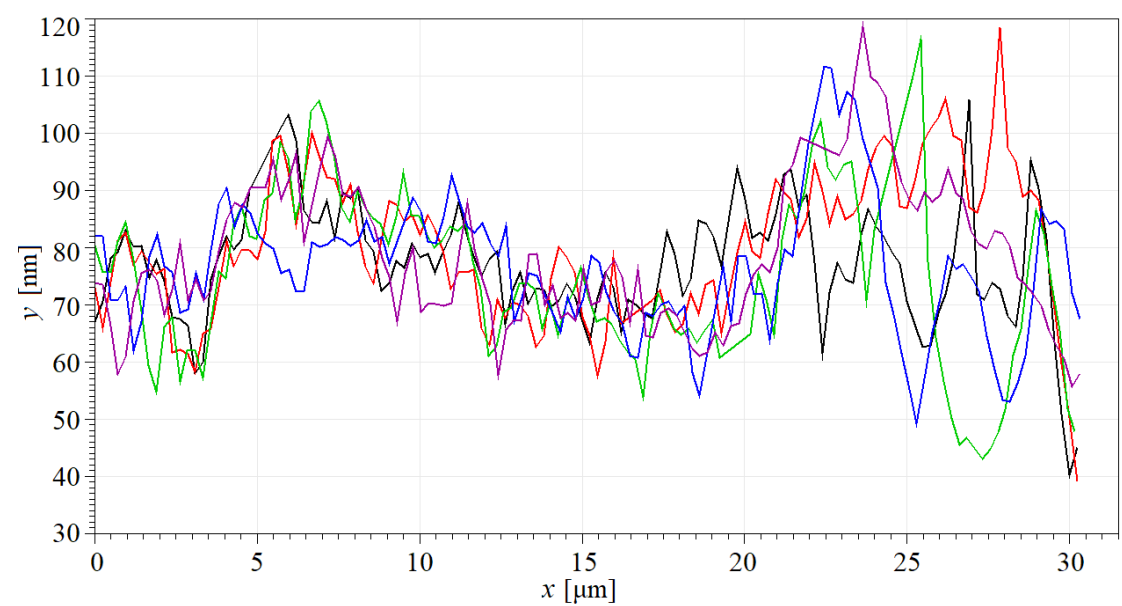

a

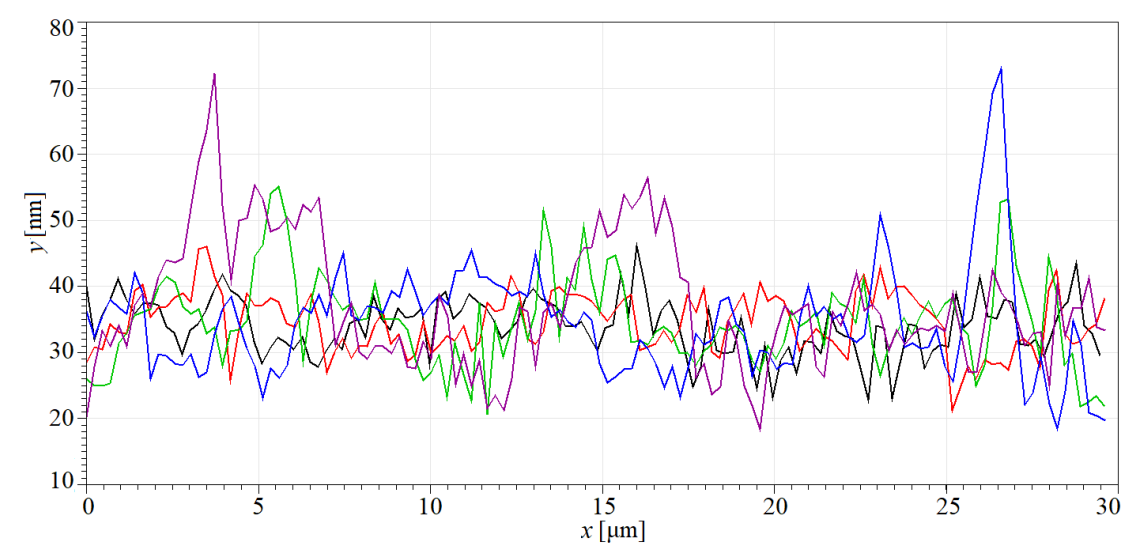

$\mathrm{b}$

Puc. 4. (Color online) Профили образцов 1 (а) и 2 (b) в направлении оси X изображения.

Fig. 4. (Color online) Profiles of samples 1 (a) and (b) in $\mathrm{X}$ axis direction of image.

Табл. 2. Статистические параметры и фрактальная размерность образцов.

Table 2. Statistical parameters and fractal dimension of the samples.

\begin{tabular}{|c|c|c|}
\hline Параметр / Parameter & Образец 1/ Sample 1 & Образец 2/ Sample 2 \\
\hline Средняя шероховатость, нм /Average roughness, nm & $7.13 \pm 1.10$ & $8.72 \pm 1.17$ \\
\hline Среднеквадратичная шероховатость, нм /Root mean square roughness, nm & $9.74 \pm 1.16$ & $12.13 \pm 1.22$ \\
\hline Асимметрия / Asymmetry & $0.47 \pm 0.02$ & $-0.604 \pm 0.024$ \\
\hline Эксцесс / Excess & $5.72 \pm 0.19$ & $3.06 \pm 0.13$ \\
\hline Максимальная высота пика, нм / Maximum peak height, nm & $97.07 \pm 4.10$ & $86.71 \pm 3.76$ \\
\hline Максимальная глубина впадины, нм / Maximum cavity depth, nm & $53.71 \pm 2.36$ & $64.02 \pm 2.80$ \\
\hline Фрактальная размерность / Fractal dimension & $2.239 \pm 0.038$ & $2.360 \pm 0.035$ \\
\hline
\end{tabular}




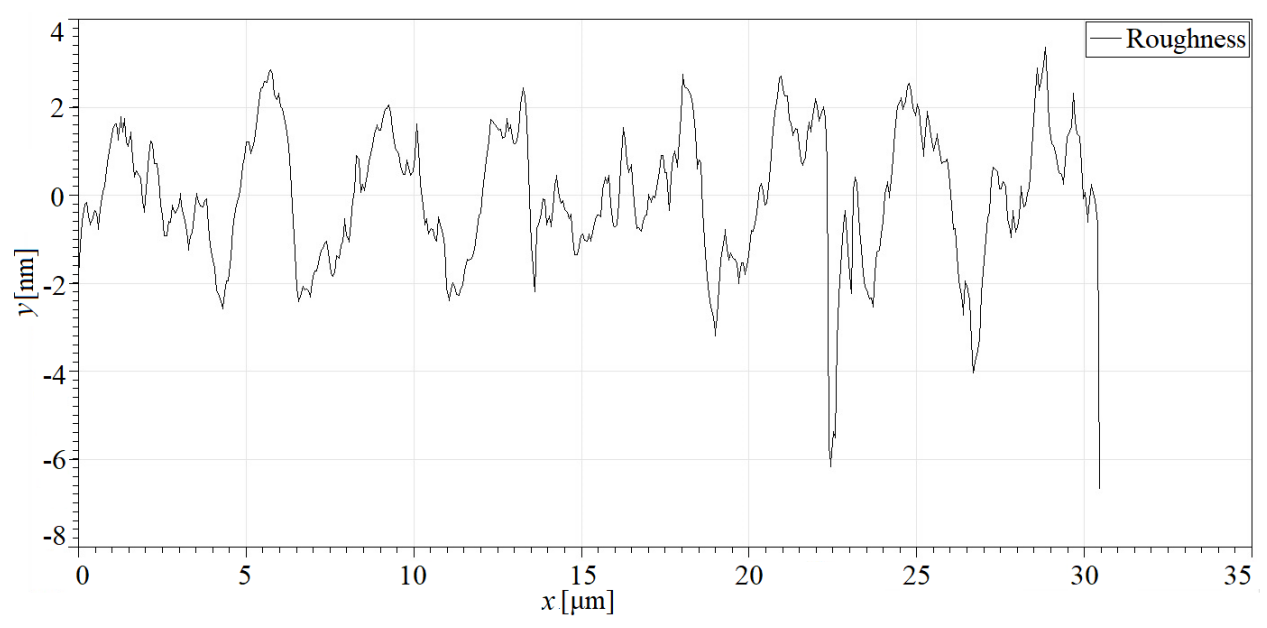

Рис. 5. Шероховатость образца 2.

Fig. 5. The roughness of sample 2 .

\section{Заключение}

Для изучения структурных особенностей композита на основе стали $14 Г 2$ применены оптическая микроскопия и АСМ. Проведен анализ рельефа и получена информация о его топологии посредствам измерения шероховатости, вычисления асимметрии и эксцесса. Сравнение полученных результатов показало, что поверхность со строчечной структурой несколько более развита, чем поверхность с однородной троосто-мартенситной структурой. Возможно, для стали с большим содержанием углерода и/или легирующих элементов данное отличие будет значительнее. Результаты свидетельствуют о возможности применения АСМ для исследования структуры композита на основе конструкционной стали с исходной строчечной структурой. Однако, требуется комплексный подход к изучению структуры стали на наноуровне, например, применение СЭМ и АСМ.

Дополнительныйматериал/Supplementarymaterial. Электронная версия статьи содержит дополнительный материал (Рис. S1), доступный безвозмездно на сайте журнала (lettersonmaterials.com). / The online version of this paper contains supplementary material (Fig. S1) available free of charge at the journal's Web site (lettersonmaterials.com).

\section{Литература/References}

1. V.N. Pustovoit, Yu. M. Dombrovskii, V. V. Lavrichenko. Uspekhi sovremennogo yestestvoznaniya. 3, 57 (2005). (in Russian) [В.Н. Пустовойт, Ю.М. Домбровский, B.В. Лавриченко. Известия высших учебных заведений. Черная металлургия. 3 (15), 5 (2006).]

2. V.N. Pustovoit, Yu. V. Dolgachev, V. V. Duka. Izvestiya Volgogradskogo gosudarstvennogo tekhnicheskogo universiteta. 10 (205), 118 (2017). (in Russian) [В.Н. Пустовойт, Ю.В.Долгачев, В.В.Дука. Известия Волгоградского государственного технического университета.10 (205), 118 (2017).]
3. V.N. Pustovoit, Yu. V. Dolgachev, V.V. Duka, L.P. Aref'eva, V.V. Fedosov, V.M. Salynskikh. MATEC Web of Conferences. 226, 03006 (2018). Crossref

4. A.S. Zubchenko, M.M. Koloskov, Yu.V. Kashirskiy Marochnik staley i splavov (ed. by A.S. Zubchenko). Moskow, Mashinostroyeniye (2003) 784 p. (in Russian) [А.С. Зубченко, М.М. Колосков, Ю.. Каширский. Марочник сталей и сплавов (под ред. А. С. Зубченко). Москва, Машиностроение (2003) 784 с.]

5. P.G. Ul'yanov, D. Yu. Usacheva, B. V. Sen 'kovskiy, K. I. Borygina, F. A. Nikolayev, V.K. Adamchuk, S. V. Pushko, A.A. Mal'tsev, K.S. Balizh. Vestnik SPbGU. Ser. 4. 4, 43 (2012). (in Russian) [П. Г. Ульянов, Д. Ю. Усачева, Б.В. Сеньковский, К.И. Борыгина, Ф.А. Николаев, В.К. Адамчук, С.В. Пушко, А. А. Мальцев, К. С. Балиж. Вестник СПбГУ. Сер. 4. 4, 43 (2012).]

6. L.P. Aref'eva, I. G. Shebzukhova. Physical and chemical aspects of the study of clusters, nanostructures and nanomaterials. 10, 27 (2018). (in Russian) [Л. П. Арефьева, И. Г. Шебзухова. Физико-химические аспекты изучения кластеров, наноструктур и наноматериалов. 10, 27 (2018).] Crossref

7. L.P. Aref'eva, A.V. Blinov, A.A. Kravtsov, I. G. Shebzukhova, A. V. Serov. Matec Web of Conferences. 226, 03009 (2018).] Crossref

8. L.B. Zuyev, G.V. Shlyakhova. Materialovedeniye. 7, 7 (2014). (in Russian) [Л.Б. Зуев, Г.В. Шляхова. Материаловедение. 7, 7 (2014).]

9. I. A. Pankratov, I. N. Stepankin. Zavodskaya laboratoriya. Diagnostika materialov. 83 (7), 40 (2017). (in Russian) [И.А. Панкратов, И.Н. Степанкин. Заводская лаборатория. Диагностика материалов. 83 (7), 40 (2017).]

10. M. B. Rigmant, M. K. Korkh, D. I. Davydov, D. A. Shishkin, Y. V. Korkh, A.P. Nichipuruk, N. V. Kazantseva. Russian Journal of Nondestrructive Testing. 51 (11), 680 (2015). Crossref

11. V. V. Duka, V. N. Pustovoit, L. P. Aref 'eva, D. A. Ostapenko, Yu. M. Dombrovskii. IOP Conference Series: Materials 
Science and Engineering. 680, 012023 (2019). Crossref

12. G. V. Shlyakhova, L.B. Zuyev, Ye.A. Popova. Vestnik Tambovskogo universiteta. Seriya Yestestvennyye i tekhnicheskiye nauki. Prilozheniye k zhurnalu. 23 (123), 581 (2018). (in Russian) [Г. В. Шляхова, Л.Б. Зуев, Е.А. Попова. Вестник Тамбовского университета. Серия Естественные и технические науки. Приложение к журналу. 23 (123), 581 (2018).] Crossref

13. G. V. Shlyakhova, S. A. Barannikova, L. B. Zuyev. Vestnik Tambovskogo universiteta. Seriya Yestestvennyye i tekhnicheski nauki. 21 (3), 1447 (2016). (in Russian) [Г.В. Шляхова, С. А. Баранникова, Л. Б. Зуев. Вестник Тамбовского университета. Серия Естественные и технически науки. 21 (3), 1447. (2016).] Crossref

14. S. A. Barannikova, G. V. Shlyakhova, L. B. Zuyev. Vestnik Tambovskogo universiteta. Seriya Yestestvennyye i tekhnicheski nauki. 21 (3), 882 (2016). (in Russian)
[С. А. Баранникова, Г. В. Шляхова, Л. Б. Зуев. Вестник Тамбовского университета. Серия Естественные и технически науки. 21 (3), 882 (2016).] Crossref

15. G. V. Shlyakhova, L. B. Zuev, E. A. Popova. AIP Conference Proceedings. 2053, 030063 (2018). Crossref

16. V.S. Ivanova, A. S. Balankin, I. Zh. Bunin, A. A. Oksogoyev Sinergetiks and fraktals in material science. Moscow, Nauka (1994) 383 p. (in Russian) [В.С. Иванова, А.С. Баланкин, И.Ж. Бунин, А.А. Оксогоев. Синергетика и фракталы в материаловедении. Москва, Наука (1994) 383 с.]

17. GOST R ISO 4287-2014. Natsional'nyy standart Rossiyskoy Federatsii. Geometricheskiye kharakteristiki izdeliy (GPS). Data vvedeniya 01.01.2016. (in Russian) [ГОСТ P ИСО 4287-2014. Национальный стандарт Российской Федерации. Геометрические характеристики изделий (GPS). Дата введения 01.01.2016.] 